\title{
IS FORMALITY RELEVANT? JAPANESE TOKENS HAI, EE AND UN
}

\author{
Lidia Tanaka
}

\begin{abstract}
The use of particular lexical, semantic and pragmatic elements to determine the degree of formality is well recognised. In Japanese, formality in a communicative interaction is achieved not only by the use of the appropriate speech style but also of backchannels and short responses. Three such short affirmative responses that also have different pragmatic functions in Japanese are hai, ee (also variants $e$ and $e h$ ) and $u n$. Hai is considered to be the most polite while ee and un decrease in degree of formality. However, when looking at real data their use is not that clearly defined. While hai is found only in formal settings, ee and un are used just as frequently in those interactions. Hence, formality or politeness alone cannot account for their use.

This paper looks at the use of hai, ee and un in formal interviews, and shows that all three tokens are used frequently as answers, backchannels and discourse markers. However, their distribution is determined by the speakers' roles suggesting that they project a particular stance and have a distinct emotive value. It appears that hai puts the content in the foreground and is therefore mostly used by interviewees while un is hearer-centered and is more frequently used by interviewers as a backchannel. On the other hand, the ee token is used by both interviewers and interviewees but has other very different functions to hai and un. The fact that these tokens originally used as affirmative tokens are now multifunctional suggests that they are going through a process of intersubjectification.
\end{abstract}

Key words: Japanese; Response tokens; Hai; Ee; Un.

\section{Introduction}

In any communicative interaction, speakers make linguistic choices that determine the degree of formality and the social distance they want to establish between themselves and their interlocutors. These linguistic choices display varying degrees of complexity in different languages. Examples include the honorific system, a set of personal pronouns $(\mathrm{T} / \mathrm{V})$, address terms and lexical choice. Even the selection of a simple answer such as 'yes' or 'yeah' gives the listener pragmatic information that establishes the tone of the interaction.

Unlike the English affirmative token yeah, that is described as a discourse marker (Fuller 2003; Gardener 2001; Jucker and Smith 1998), the Japanese affirmative tokens have been explained in terms of formality and politeness. Hai is considered to be the most formal affirmative answer, $e e^{1}$ is less formal and un is associated with very

\footnotetext{
${ }^{1} \mathrm{Ee}$ has the shorter variants $e$ and $e h$
} 
casual and informal speech (Guruupu Jamashii 1998). Ee and un have been largely ignored by researchers (except for Hayashi 2009 and Togashi 2002). However, hai has been the focus of interest, in particular, for grammarians (Kitagawa 1980; Kuno 1973; Okutsu 1989). They have been interested in the use of hai as a response to Y/N questions because it is used to give positive answers when negative questions are asked. However, hai, un and ee are used not only as affirmative responses but as multifunctional tokens. These functions vary depending on their position in the discourse. They appear turn-initially, turn-internally and turn-finally and are also used as backchannels (Angles, Nagatomi and Nakayama 2000; Kitagawa 1980; Hayashi 2009; Togashi 2002). Turn-initial tokens are those used in direct response to a question, suggestion or invitation. Turn-internal tokens are mainly used as fillers while turn-final tokens are used to stress a point or as a turn-giving cue. When used as backchannels they have no propositional meaning and are optional.

While the token hai is seldom used in conversations among friends, except in a humorous way or in duplicated forms, the same restrictions do not govern the use of un and ee (Angles et al. 2000). In other words, as seen in this study, the tokens un and ee, usually described as less 'formal', are used in formal interactions with similar frequency to hai. This suggests that politeness is indeed one aspect; however, other reason(s) aside from formality must be explored in order to fully understand the differences in their use. Many scholars have indicated that every linguistic element is marked with emotive interpersonal information (Caffi and Janney 1994; Danes 1994; Maynard 2002) and the Japanese language appears to code expressive functions in a relatively explicit manner (Akio 1997; Matsumoto 1988; Maynard 2002; Suzuki 2006). Even a simple statement like 'Today is a nice day' carries affective information that denotes the speaker's attitude towards the listener (Matsumoto 1988). Therefore, looking at the tokens hai, ee and un from the perspective of emotive communication might provide a deeper understanding and enable us to answer some of questions in relation to use of these tokens ${ }^{2}$.

Thus far, none of the studies on hai, ee and un have explained why the latter two are used so frequently in formal interactions. There are studies of these tokens from the viewpoint of backchannel behaviour (Komiya 1986; Kurosaki 1987); however, they do not discuss the possible reasons for their use in informal interactions. More importantly, to my knowledge, these tokens have not yet been looked at from the viewpoint of emotivity.

The seemingly multifunctional nature of hai, ee and un would seem to suggest that the use of these tokens is undergoing a process of change. It has been argued that meaning change progresses from original meanings, that take a more speaker oriented focus known as subjectification, towards a more addressee centered meaning or intersubjectification (Traugott 1995, 2007; Traugott and Dasher 2002). In particular many discourse markers had gone through intersubjectification and the fact that these tokens are multifunctional and polisemantic suggests that a similar process is taking place (Onodera 2004; Suzuki 2006).

Similarly, even though most scholars agree that hai, in particular, is multifunctional, their data is not based on real conversations and there have been almost no attempts to look into why or how these tokens have come to be used with different functions (with the notable exemption of Hayashi 2009 and Togashi 2002). It is necessary to look at how hai, ee and un are actually used in the discourse and at the relevance of this for the speakers (Sacks, Schegloff and Jefferson 1974).

This study analyses the responses hai, ee and un in twenty one formal dyadic interactions from television and also from another set of formal interviews to determine why 'informal' tokens are used in formal interactions. Taking both a qualitative and quantitative approach, this paper looks at where they occur in a turn and what function they have. It also includes an analysis of their distribution and frequency. The results

\footnotetext{
${ }^{2}$ The author is indebted to the anonymous reviewer for this suggestion.
} 
show that all three tokens are used frequently in the discourse and that hai is overwhelmingly used by interviewees while un is mostly used by interviewers. This fact indicates that the role of the speaker is an important factor in their use and distribution; but, most importantly, their affective stances or emotive values are different. Hai seems to be more related to the content of the talk rather than to the interpersonal relations; un is used to encourage and promote talk and is listener oriented. On the other hand, ee is used by both hosts and guests. The fact that these tokens are overwhelmingly used as backchannels and discourse markers suggests that a process of intersubjectification is taking place where their function is increasingly more related to the management of the discourse rather than to giving affirmative answers (Traugott and Dasher 2002).

\section{Past studies}

Research regarding hai, ee and un can be classified into two different approaches. The first approach is found in traditional studies that have concentrated on the token hai because of its particular usage when answering $\mathrm{Y} / \mathrm{N}$ questions, which differs to that of other languages (Martin 1962; Kuno 1973). More recent researchers have focused on the fact that when the Japanese answer negative questions with the affirmative 'hai' or the negative 'iie' they use these in a way that is the reverse of English. Japanese speakers use hai to accept and iie to deny the description of the truth, and not to affirm or deny a question (Martin 1962). However, there are counter-examples to this statement suggesting that what is more important is not whether the question is in the negative form or not, but whether the questioner expects an affirmative or a negative answer (Kuno 1973: 180).

The second approach looks into hai's other functions and compares them with ee and un, and is more discourse based (Angles et al. 2000; Kitagawa 1980; Okutsu 1989; Togashi 2002). Researchers have added a different perspective arguing that hai not only functions as a response but that it works as a 'signal'. The use of hai satisfies two of the maxims of Grice's Maxim of Quality: Manner (be clear) and Quality (do not make your contribution more informative than required) (Kitagawa 1980).

Hai has also been studied in contrast to iie and the results show that Japanese speakers tend to use more affirmative responses than negative ones because responding with affirmative tokens functions to maintain a friendly and harmonious relationship (Okutsu 1989).

Others argue that these tokens are not only dependent on formality but that they also have different functions. Hai seems to be the most inclusive of these tokens and its fundamental function is to promote discourse (Angles et al. 2002). While hai's fundamental function is to promote further discourse, the function of ee and un is that of a backchannel. Through a contrastive analysis of examples of situations when these tokens can and cannot be used, Angles et al. argue that hai is the most inclusive and ee is the most restrictive (2002). They identified five functions when any one of the three tokens can be used: a) positive answer to Y/N questions, b) backchannels, c) acknowledgement of having heard before answering, d) self-confirmation and e) response to a suggestion. A sixth function, f) response to a command or a strong request, also applies to hai and un. There are five other functions that are restricted to hai: g) attention getting, h) response to attention getting, i) presentation/submission, $\mathrm{j}$ ) roll call and $\mathrm{k}$ ) repeated backchannel to cut off partner's speech. Undoubtedly, this more exhaustive list of examples brings about a new understanding of how these responses are used. While it is extremely difficult to have real data for all situations in which these tokens appear, one drawback of this study is that all examples are constructed and it is not known whether these examples actually occur in real conversations or whether their distribution is quite so neat.

The difference between the use of hai and un has also been explained in terms of the degree of new information being conveyed. Using Chafe's concept of given/accessible/new information (Chafe 1994), hai seems to be better than un at 
retrieving more information related to what is being asked or said. Therefore, hai is sent as a backchannel when the information is complete while un is sent at points where it is incomplete (Togashi 2002). Similarly, when hai is used as an answer it is a response to the content of the question while un is a response to the exposition/presentation of the information. Likewise, when there is a finite point to the topic of conversation, hai appears to be used when the information is complete and un is used in such cases with less frequency.

A more recent study of the token ee looks at the various functions it has in the discourse (Hayashi 2009). All occurrences of ee (except backchannels) are included in this study and Hayashi writes that ee signals the listener's dissalignment to an assessment, to a resistance to a question or to a disjunctive shift. It is of particular interest that ee tokens with prosodic features that denote surprise and are classified as interjections by grammarians are included in his study.

Similar studies on the allomorphs of the affirmative token yes in other languages (English and Indonesian) also suggest that these words are multi-functional (Fuller 2003; Jucker and Smith 1998; Wouk 2001) and operate as discourse markers. They can be used not only as affirmative responses but also as backchannels, as discourse markers and as cooperative markers (Wouk 2001). Similarly, there seems to be a direct relation between the role of the speaker, the speech context and the frequency of use of discourse markers (Fuller 2003).

While previous studies of the Japanese responses hai, ee and un contribute enormously to the understanding of these tokens, most of them have based their observations on constructed data. If we are to argue that politeness and formality cannot fully explain the use of these tokens, it is imperative that we have authentic spoken data. Only then will we be able to understand how hai, ee and un are used in real discourse.

\section{Data}

The formal data comprises television interviews and informal interviews. Twenty one television interviews were recorded and transcribed including four formal interviews from the Kita Kyuushuu University Corpus ${ }^{3}$. The latter are interviews between a university student and an older person. The topics centre on the student's studies and university life.

Initially, this study included informal data comprising 20 dyadic conversations between friends (Usami Data ${ }^{4}$ ). However, since hai is rarely found, and when it is, it only appears in duplicated or triplicated forms, this data has been excluded from the study except for the purpose of stressing that hai is not used in informal discourse.

\section{Hai, ee and un in the discourse}

All three tokens were firstly identified and categorized according to their function, as determined by their position in a turn (Sacks et al. 1974). What occurs before and after the occurrence of the token was looked at carefully in order to determine their function. Tokens that had distinct prosodic features were excluded from the analysis as they can be categorized as interjections or fillers. These included fillers and exclamations like those in the following excerpt. The token ee in line 1 is characterized by the lengthening of the vowel and it functions as filler. Other similar linguistic devices such as the use of ano and sono in the same line, and also the slight pause, are evidence that the host is

\footnotetext{
3 The author thanks Dr Ryuuichi Uemura of Kita Kyuushu University for kindly providing the interview data.

${ }^{4}$ The author thanks Dr Mayumi Usami of Tokyo University of Foreign Languages for kindly providing the informal data.
} 
thinking. They operate as a strategy for the host to hold the floor and give himself time to think about his next question.

$(1)^{5}$

$1 \mathrm{H}$ : [ano. kono naka ni wa sono, $\boldsymbol{e}==$,, Ohira san ga ne/ (hai.) korehodo

2 bengoshi no katsudoo ni jissai ni ((continues))

' $\mathrm{H}$ : Uhm, in this, well, $\mathrm{e}==\ldots$ That you (hai) could be so active

as a lawyer ((continues))

\subsection{Turn-initial tokens}

\subsubsection{Hai and ee as answers to Y/N questions}

The canonical use of hai typically described in grammar and language textbooks is seen in example (2). This excerpt is from an interview where the guest is a writer. Here, the host had asked the guest about one of his books written for teenagers who were starting to think about a career. In line 4, the host asks about the word matagi in the $\mathrm{Y} / \mathrm{N}$ question form (Noun + copula desu + question particle kai) because it is a rarely used term, and the guest responds with the token hai (line 5). Notice that turn-taking is smooth and there are no pauses or false starts indicating that this is a preferred answer (Pomerantz 1984). On the other hand, we can see how the tokens ee and un are used as backchannels (lines 1-3). Note that a backchannel is sent after the conjunctive particle de (line 5) and it is difficult to understand its function as being anything other than encouraging the guest to talk.

1 G: $\quad$ aete iretakatta no wa (ee) tatoeba shokubutsu ga suki (XX) ni naru

2 purantohantaa toka desu ne. (ee) doobutsu ga suki (XX) matagi

3 toka (ee).

$4 \mathrm{H}$ : @@ matagi desu ka?

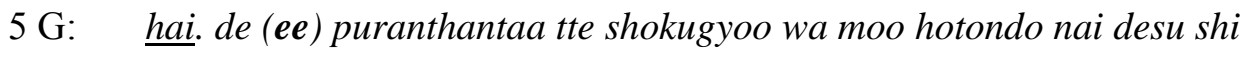

6 (un). ma. purantohantaa tte iu no wa ano= (un)... juukyuuseiki koro no

7 yooroppa de (un)

'G: What I wanted to include (ee) [in my book] was for example plant hunters who come to like plants, you see (ee) others like matagi (ee) come to like animals (XX)

H: @@@ Is it 'matagi (hunter)'?

G: Hai, and (ee) the profession of plant hunter is almost non-existent now (un) well plant hunters were uhm (un) in 19th century Europe (un)'

\footnotetext{
${ }^{5}$ See appendix for transcription conventions. $\mathrm{H}$ : Host or interviewer; G: guest or interviewee
} 
Similarly, the token ee is used to answer Y/N questions in exactly the same manner as hai. In (3) the interviewee is a professional photographer of insects whose works are unique in the sense that the photographs are taken from the point of view of the insect rather than the human being. In lines 1-3 the interviewer asks him if one of his goals is to raise awareness and interest in nature among his viewers. Note that there is an overlap right after the particle mo, however, there is no doubt as to the intended question. There are a number of possibilities for the turn completion after the quotative particle to that follows the conjunctive particle $b a$, however, the listener understands it as a question and prematurely starts his turn. It is indeed one of the characteristics of Japanese turn taking that the majority of turn endings are syntactically incomplete (Lerner and Takagi 1999; Mori, J. 1999; Tanaka, H. 1999; Tanaka, L. 2004), therefore the guest had no difficulty understanding the intended question.

$1 \mathrm{H}$ : $\quad$ soo suruto soo itta = sono kyoomi = o okosaseru hitotsu no, kikkake ni

2 sono Kuribayashi san no shashin ga nareba-tto mo [kangaetteru $n$ desu

$3 \quad k a$ ?

$4 \mathrm{G}$ :

[ee. tsuneni sou

5

omottemasu. watashi mo= hitotsu no shimei to iimasu ka ne/

'H: Then, do you (Mr Kuribayashi) think that you photographs are going to make people [interested in (nature)?

G:[ee. I always think so. I think that it is one of my life goals, you see?'

This is a counterexample of what Hayashi (2009) reports in his study on the use of eh. He wrote that an eh-prefaced answer 'appears to register its producers' stance that the question addressed to him/her embodies a move that departs from his/her expectation or supposition (Hayashi 2009: 2122). However, in our example it is evident that the interviewee agrees with the interviewer's question and that ee is used as an affirmative token.

\subsubsection{Answers to Wh-questions}

Hai was also found in turn-initial position as an answer to Wh-questions as in example (3). The guest in this program talks about her Not for Profit Organisation (NPO) set up to help disabled people and give them work. In lines 1 and 2 the host asks about the nature of the organization and the guest answers her turn with hai. The interviewer's question is a typical Japanese Wh-question ending with the particle $k a$ (Wh-word: dou iu 'what kind'). The guest starts her turn with the token hai as a turn-taking device to show that she is ready to take the floor. The number of fillers and lengthening of the vowel ( $a n o=$ 'uhm' and daitai 'generally speaking') before she produces her answer shows that although she has taken the floor she needs some time to think: She is trying to formulate a good description of her organization.

$1 \mathrm{H}$ : $\quad$ purpoppu suteeshoon to iu no wa (hai) doo iu katsudoo o suru tokoro 
$2 \quad$ nan desu [ka?

$3 \mathrm{G}: \rightarrow \quad$ [hai. ano= daitai ima (ee) hayari no desune (ha) konpyuutaa ya

$4 \quad$ intaanetto o katsuyoo shite. (hai) shoogai o motsu hitotachi ga (ee)

$5 \quad$ zaitaku de demo (hai)

'H: At Prop Station (hai) what kind of activities do you [do?

G: [Hai. Uhm= Generally, we are using (ee) (ha) computers and

the internet which are so popular now (hai) so that disabled

people (ee) can [work] at home (hai)'

Interestingly, half of the guests use ee turn-initially than hai as a response to Wh-questions or syntactically incomplete turns. In the following excerpt, the host asks his guest, a famous jockey, to explain how he feels about the Derby. The question has a typical Wh-question structure: The topic followed by a pause and then the question ending $k a$.

$1 \mathrm{H}$ : $\quad$ getsumatsu ni wa DAABII mo (hai) arimasu keredomo... donna kimochi

2 de irasshaimasu ka?

$3 \mathrm{G}: \rightarrow \underline{e} .$. ano=... ma wareware kishu ni tottewa ne? (un) moo sugoku, machi ni

$4 \quad$ matta kisetsu to iu ka.

'H: The Derby is going to be at the end of the month (hai)... but how do you feel about it?

G: E. uhm- well, for us jockeys (un) it is the season that we have all been waiting for...'

From these two examples, it seems that starting a turn with either hai or ee in response to a Wh-question or a syntactically unfinished turn signals a turn-taking cue. The fact that what follows after hai and ee, when uttered turn-initially in response to either a Wh-question or a statement, are overwhelmingly fillers with prosodic features suggests that interlocutors use hai and ee to indicate they are taking the floor even though they might not be really ready to answer the questions immediately.

\subsubsection{Response to requests}

These tokens are also used in response to requests as mentioned by Angles et al. (2002). The next example is an excerpt from a different interview with a guest who is a founder of an NPO that provides jobs for disabled persons. The host asks the guest to elaborate on a concept regarding disabled persons and their status as tax payers. Note that the question takes the form of a request: Noun + Verb (Potential) $+k a$. The guest starts her turn with the token ee (line 2) in response to the host's request. 
$1 \mathrm{H}: \quad$ sono (ee) okangae (hai) chotto moo sukoshi ohanashi itadakemasu ka?

$2 \mathrm{G}: \quad$ ee. Ano kono noozeisha charenjiddo noozeisha tte iu kotoba jishin wa

3 desune (hai) watashi ga hajime no iidashippe de wa nakute (hai) ka no

4 jon efu kenedi daitooryoo (ee)

'H: That (ee) idea (hai), could you talk about it a little more?

G: Ee. Well this tax-payer challenged, this term itself (hai) it is not me who started using it (hai) it was the late President John F. Kennedy (ee)'

\subsection{Hai, ee and un as discourse markers}

\subsubsection{Turn-taking cues}

Initial hai was also found as an answer to non-question forms or after grammatically unfinished forms. It has been well-documented that syntactic completion is not a requirement for turn-taking in Japanese, and that speakers have no problems in understanding possible transition relevance places (TRPs) (Furo 2001; Tanaka, H. 1999; Tanaka, L. 2004). In example (7) the guest interviewed works for a non-profit organization that removes landmines in many countries around the world. The host and guest are talking about how the landmines work. In line 1, the host explains that if anyone should step on a particular part of the landmine it would explode. The guest takes the floor and starts her turn with hai even though the host's turn is grammatically unfinished and there are no other prosodic features that might indicate interrogativity. The fact that the turn is syntactically incomplete is a very common turn-taking feature in Japanese as previously mentioned and the guest in this example interprets a TRP after a conditional (Mori, J. 1999; Onodera 2004; Tanaka, H. 1999; Tanaka, L. 2004). The second hai in line 5 is also turn-initial and functions as a turn-taking cue. The host in line 4 uses an interjection hoo to indicate deep interest in the topic.

$1 \mathrm{H}$ : de koko, koo pon to, fumuto

$2 \mathrm{G}$ : $\quad$ hai. ano, gokiro ijoo no omosa ga kuwawaruto, hontooni ningen de

3 attemo, soo janakutemo

$4 \mathrm{H}: \quad$ Hoo

5 G: hai. desukara gokiro ijoo de areba doobutsu demo mochiron

6 bakuhatsu shimasu. Hai.

'H: and if you step lightly here

G: Hai well, any weight over 5 kilograms, human being or other

H: Really

G: Hai. So as long as that something is heavier than 5 kilograms, even an animal, it will explode. Hai'. 
The final occurrence of hai in line 6 will be explained in a subsequent section.

$\mathrm{Hai}$, ee and un are also used turn-initially after grammatically complete statements. In the next extract, the guest is a reformed lawyer who had been a member of a delinquent group as a teenager and had also joined the Japanese yakuza. Here she talks about having a tattoo, which is a symbolic entry to the world of the yakuza (a mafia-like organisation) in Japanese society. Note how the host starts his turn in line 1 with the token un which functions as a turn-initiator. This is followed by the word irezumi 'tattoo' and functions almost as a question because the guest responds with hai (line 1) to confirm the information. In line 2, the guest starts her turn with hai even though the host's turn does not have the traditional question structure that ends with the particle $k a$. Note that there is an overlap with the host's particle ne and rising intonation that might work as a question. However, the lack of pauses or fillers indicates that the guest was ready to take the floor.

$1 \mathrm{H}: \quad$ un. irezumi (hai) o/ irerarerun desu [ne/

$2 \mathrm{G}$ : [hai.] sono sekai ni haittta toki ni/(ee)

3 yappari juu-rokusai deshita kara, (juurokusai.) mawari ga ukeirete

3 kurenain desu ne/ (un) doose, ano=, kimama de/ (un)

' H: un. tattoo (hai) you had it done, right?

G: hai. when I entered that world (ee) well I was sixteen so

(sixteen) the people around you do not accept you (un) (they

think that) I would surely be uhm, selfish and (un)'

The data contained further examples of ee as an initial token with the same function as in examples (7) and (8). The host and guest in interview (9) are looking at the photograph of a wasp taken by the guest. The host gives his comment in line 2 and, as in the previous example, it is a syntactically unfinished turn. In line 3, the guest takes the floor and starts his turn with the token ee. It seems that ee in this example functions as a turn-taking signal and also as a means of agreeing with the host. By uttering ee, the guest shows his host that he is taking the floor and will contribute to the unfinished question or request.

$1 \mathrm{H}$ : $\quad$ suzumebachi no masani kono- shunkan o kiritotta youna (ee) migoto na

2 shashin desu keredomo.

$3 \mathrm{G}$ : ee. tonde= kamera ni mukattekite, osoraku desu ne/ me no mae ni aru

4 kamera ni taishite $k o u==$ okotte ikaku shiteru= shunkan janai ka to

5 omoun desu nel

' $\mathrm{H}$ : It is a great photograph of a bee taken when it was in the moment (ee) of

G: Ee. It was when the bee was flying towards the camera, probably. I think that

it was the moment when $u h m=$ the bee was angry and= tried to attack the camera.' 
Initially occurring un was observed in the discourse of hosts. It seems that hosts used un in initial position when they were trying to understand what they had been told and needed more information, or when they wanted to express their interest in the topic. The next example is one in which the host shows his interest in the narration. The guest is the female lawyer from example (8). Here, she is recounting how she got a tattoo. In Japan, the signature of a parent is needed for under age people who are going to be tattooed. The host starts his turn in line 4 with the token un and asks whether it was she who had lodged the form, which is an interesting turn as it is obvious from what she had previously said that it was she herself who went to her parents' house.

$1 \mathrm{G}$ : chichi mo haha mo shokujichuu dattan desu kedomo/ (un) ima kara sumi

2 tsuku kara/ (un) kono-yooshi ni hankoo o osee tte iu fuuni kami o

3 sashidashitan desu yo.

$4 \mathrm{H}$ : un. Oohira-san ga/

$5 \mathrm{G}$ : $\quad$ hai. de soreto chichi wa moo damatte utsumuite mashite. ((continues))

'G: My father and mother were in the middle of a meal (un) and telling them that I was going to get a tattoo (un) I gave them the form

H: Un. You (Ms Ohira) did it?

G: Hai. And my father was just silent looking down and ((continues))

\subsubsection{Tokens in final position}

Hai and ee were also used in final position in the data with a completely different function to that of an answer. In example (11), the host asks her guest, whose late husband was a prominent Japanese writer, about the last days of his life. She says that he was quite healthy and did not rest much, and she ends her turn with hai. This might function as a turn-yielding cue or most probably as a way of stressing her point.

$1 \mathrm{H}$ : $\quad$ sore ga kuyashii tte (hai ) oshattanda kedomo

$2 \mathrm{G}: \quad$ hai. maeno hi made nantomo maa byooki de wa gozaimashita kedomo/

3 warito genkide yasumi mo shinazu. itan desu. hai.

'H: You said that was a shame (hai), but

G: Hai he was sick right up until the day before but/he was quite lively and did not rest. hai.'

This use is also seen in example (7) when the guest finishes his explanation that the landmine explodes when it senses a weight of more than 5 kilograms. It appears that by using final hai the speaker emphasizes the previous statement, making it stronger without sounding too aggressive. 
Using hai and ee in final position seems, therefore, to function to emphasize one's point, and as a sign of turn-yielding. A very common pattern that appears in most of the interviewees' discourse is hai after the verbal to omoimasu 'I think'. In Japanese, utterances can finish with the copula or with the verb 'to omoimasu' which functions as a hedge and therefore softens the expression. The fact that interviewees finished their turns with the verb omoimasu indicates that by adding the token hai or ee they wanted to stress their viewpoint in a non-aggressive manner.

The next example is one that includes the expression to omoimasu. Here the interviewee is explaining that members of her non-profit organization have to work under very tough conditions in order to remove land mines. Verbs like omou are regarded as hedges and are a characteristic of Japanese communication. Regardless of the conviction or assurance of the speaker in relation to a statement or opinion, Japanese will invariably end their sentences with the verb omou which softens the statement. It is therefore interesting that many of the examples in our data displayed hai and ee turn-finally. By adding these tokens, the speakers would signal turn-yielding and most importantly stress their viewpoint.

$1 \mathrm{G}$ : afugan demo gojuudoo gurai naru tokoro de minasan soo iu sagyoo o

2 tuzukete iku wake desukara, taihen na sagyoo da to omoimasu. $\underline{\text { Hai. }}$

' $\mathrm{G}$ : Because they have to continue working even when the temperature nears $50 \mathrm{C}$ in Afghanistan, I think that it is a very difficult work. Hai.'

When tokens are used in initial position they suggest that speakers understand that a question must be answered (Goody 1978) and in terms of conversational rules the first pair of an adjacency pair must be completed with the corresponding second pair (Sacks et al. 1974). The use of these tokens in turn-initial position shows the attitude of alertness and interest in the interaction on the part of the speaker. On the other hand, turn-finally occurring tokens indicate the speaker's wish to relinquish their turn or to emphasize what they have just said. The fact that they not compulsory elements, either syntactically or semantically, shows that they are discourse markers.

Although the term discourse marker is still debated (Fisher 2006; Jucker and Ziv 1998) most scholars seem to agree on a number of common features: a) they are multifunctional, b) they are short c) they are optional, d) they have little or no propositional meaning, e) they are frequent, f) they show the speaker's attitude and g) they are used for discourse management purposes (Brinton 1996; Gupta 2006).

$\mathrm{Hai}$, ee and un when used turn-initially and turn-finally do fit all the descriptions mentioned above, and they were categorized as such in the numerical analysis.

\subsection{Tokens as backchannels}

Backchannels are short responses that are sent by listeners to indicate that they are listening (Gardner 2001; Horiguchi 1997; Iwasaki 1997; Maynard 1986; Tanaka L. 2004; Yngve 1970). They are precisely timed and sent after major junctures such as noun phrases. Most of the tokens in the data were used as backchannels, as seen in the previous examples and in particular in the next two. The following is an excerpt from an interview with the guest who was a founder of an NPO that provides jobs for disabled persons (example (6)). The host asks the guest to elaborate on a concept regarding disabled persons and their status as tax payers. The guest starts her turn with the token ee (line 2) in response to the host's request. Note that again both host and guest use hai and ee as backchannels. Similarly, we can see that $e e$ is used as a response to a question or a 
request.

$1 \mathrm{H}$ : $\quad$ sono (ee) okangae (hai) chotto moo sukoshi ohanashi itadakemasu ka/

$2 \mathrm{G}$ : ee. Ano kono noozeisha charenjiddo noozeisha tte iu kotoba jishin wa

3 desune (hai) watashi ga hajime no iidashippe de wa nakute (hai) ka no

4 jon efu kenedi daitooryoo (ee)

'H: That (ee) idea (hai), could you talk about it a little more?

G: Ee. Well this tax-payer challenged, this term itself (hai) it is not me who started using it (hai) it was the late President John F. Kennedy (ee)'

Interestingly, the token un appeared to be the mostly widely used type of backchannel among the hosts while guests used the hai and ee types. The same token hai can be observed in three different positions in the next excerpt (from the same interview quoted in examples (6) and (13)). It occurs immediately after the host mentions her name, after the second clause and after the term 'challenged'. Notice that the token ee is also used, but the data suggests no particular explanation that could account for these choices.

$1 \mathrm{H}$ : namisan wa (hai) sono o = shoogai no aru kata o/ (hai) charenjiddo eigo

2 no charenjiddo (hai) to iu fuuni yobareru soo desune/ (ee) kore wa doo iu

$3 \quad$ koto kara desu $\mathrm{ka} /$

' $\mathrm{H}$ : I hear that (ee) you (hai) uhm, use the English word challenged (hai) to refer to people with disabilities (hai), where does this come from?

The following example, in which a famous Japanese writer is interviewed, shows the contrasting use of the token un. Observe the repeated use of ho by the host in lines 2 and 6. These are interjections used to indicate interest and admiration, and are usually accompanied by prosodic features such as vowel lengthening as seen in example (7). Here the author, who is in the habit of staying at a hotel while writing a novel, talks about his day as a writer.

$1 \mathrm{G}$ : maa gozenchuu no osoi jikan desu nel

$2 \mathrm{H}: \quad h o=[=$.

$3 \mathrm{G}$ : [de] maa yonaka sugi made kaite (un)... yoru wa= (un)= ano... ANMARI

4 yoru made soo iu jootai tsuzukeru to (un) nemurenakunacchau $n$ de

5 koo...koofun[shichatte]...(un)ano=...nanka...@@

$6 \mathrm{H}: \quad[\mathrm{ho}=]$

7 G: ittakiri kaettekonai yoo na kanji ni nattekuru kara. (@ @) 
The use of un by the host indicates his interest and cooperative stance in the interaction, aspects of this token which have been described by many scholars on the use of backchannels (Horiguchi 1997; Iwasaki 1997; Maynard 1986; Tanaka L. 2004).

\section{Quantitative analysis}

The total number of tokens in the sample data was 3687, and despite the fact that all the interactions are formal, the majority of tokens were of the un type (1474). Hai and ee tokens were used with almost the same frequency (1073 and 1140). However, looking at the distribution by roles, the hosts use mostly un while the guests use hai more than the other two tokens.

Table 1 Distribution of hai, ee and un

\begin{tabular}{c|lll|l} 
& hai & ee & un & \\
\hline Host & 246 & 727 & 1382 & \\
\hline Guest & 827 & 413 & 92 & \\
\hline \hline & 1073 & 1140 & 1474 & 3687 \\
\hline \hline
\end{tabular}

Figure 1 Distribution of hai, ee and un

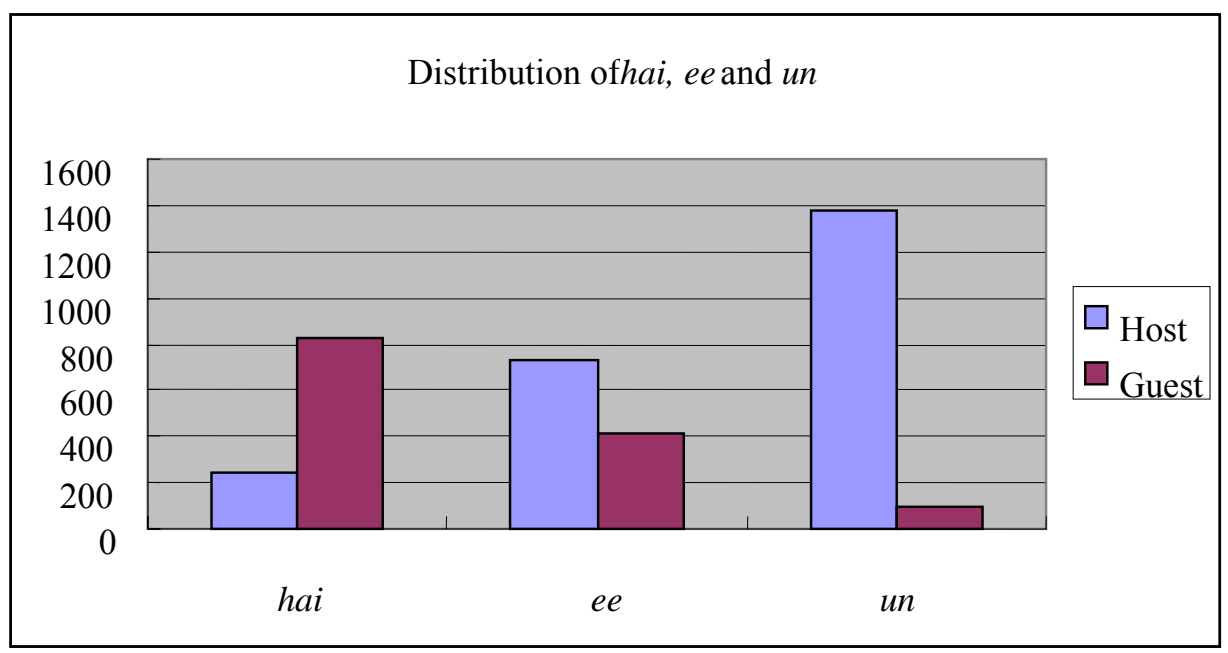

The three tokens hai, ee and un fall into three categories defined by their position in the discourse: Responses, backchannels and discourse markers. There were clear and considerable differences in the distribution of these tokens depending on the role of the speakers. Hosts use mostly un and ee tokens as backchannels while guests overwhelmingly use hai with the same function. Similarly, in the guests' discourse hai 
is the most frequent form of answer and discourse marker, followed by the ee token. Another significant difference was the use of tokens as discourse markers. The hosts rarely use them whereas the guests do. It is particularly interesting that even in the use of discourse markers (turn-initially and turn-finally), guests use the hai token more frequently than ee. (see Table 2).

Table $2 \mathrm{Hai}$, ee and un as answers, backchannels and discourse markers

\begin{tabular}{l|l|l|l|l|l|l|l|l|l}
\hline & $\begin{array}{l}\text { ai } \\
\mathrm{BC}\end{array}$ & $\begin{array}{l}\text { hai } \\
\text { answer }\end{array}$ & $\begin{array}{l}\text { hai } \\
\mathrm{DM}\end{array}$ & $\begin{array}{l}\text { ee } \\
\mathrm{BC}\end{array}$ & $\begin{array}{l}\text { ee } \\
\text { answer }\end{array}$ & $\begin{array}{l}\text { ee } \\
\mathrm{DM}\end{array}$ & $\begin{array}{c}\text { un } \\
\mathrm{BC}\end{array}$ & $\begin{array}{l}\text { un } \\
\text { answer }\end{array}$ & $\begin{array}{l}\text { un } \\
\text { DM }\end{array}$ \\
\hline Hosts & 215 & 18 & 13 & $\underline{\mathbf{7 1 3}}$ & 11 & 3 & $\underline{\mathbf{1 3 4 1}}$ & 31 & 10 \\
\hline Guests & $\underline{\mathbf{6 5 0}}$ & $\underline{\mathbf{1 0 3}}$ & $\mathbf{7 4}$ & 262 & $\underline{\mathbf{1 2 3}}$ & $\mathbf{2 8}$ & 74 & 17 & 1 \\
\hline Total & 865 & 121 & 87 & 975 & 134 & 31 & 1415 & 48 & 11 \\
\hline
\end{tabular}

BC: backchannels, DM: discourse markers

While some interviews exhibited a very high number of these tokens, others were not so which prompted me to analyse and compare intra-speaker variation across speakers. Once the distribution within each interview was obtained, tendencies and patterns were compared as seen in the following tables.

Table 3 Number of hosts/guests using hai, ee and un as affirmative answers

\begin{tabular}{c|c|c|c|c|c}
\hline use & More hai & More ee & Both hai and ee & More un & None $^{6}$ \\
\hline Hosts & 1 & 1 & 3 & 1 & 11 \\
\hline Guests & 6 & 7 & 4 & 1 & 3 \\
\hline
\end{tabular}

As seen in Table 3, only one host used hai as an answer which is not surprising as guests rarely ask questions, and very few used the other two tokens as answers. On the other hand, 6 guests used hai as answers and 7 used ee more than any other token. Only one guest used the informal un token as an answer. There were 3 guests that did not use any tokens.

The use of backchannels is summarised in Table 4. Here again, we can see that patterns are influenced by speaker role, in particular in regard to the use of hai and un. Guests tend to use hai for backchannels while hosts tend to use un. The token ee, on the other hand, is used by almost the same number of hosts and guests.

Table 4 Distribution of backchannels

\begin{tabular}{l|l|l|l|l}
\hline Use & More hai & More ee & More un & All three \\
\hline Hosts & 1 & 7 & 12 & 1 \\
\hline Guests & 12 & 8 & 1 & 0 \\
\hline
\end{tabular}

${ }^{6}$ None or negligible (once or twice). 


\section{Discussion}

The tokens ee and un are widely used in the interviews regardless of the fact that the situation is formal. They appear turn-initially, turn-finally and are used as backchannels. Hai and ee are frequently used turn-initially in the second pair of an adjacency pair and they function as turn-taking cues. The first pair in these cases can be a Wh-question, a syntactically unfinished statement or question, or a complete statement. Hai and ee are used mostly by guests, seemingly to indicate that they are taking the floor even though they might not be ready to answer or provide the requested information immediately.

On the other hand, when they appear turn-finally they are used to emphasize what the speaker has just said and, in particular, guests use them after expressions ending in hedges (for example, the verb to omou 'to think'). As has often been pointed out, Japanese tend to 'finish' their turns using either hedges or leaving their turns syntactically unfinished as a politeness strategy so as to diminish the imposition (McGloin 1990; Okamoto 1985; Tanaka L. 2004). Turn-final tokens seem to function as turn-yielding devices by indicating finality.

Although there is variation between speakers, a number of tendencies were found, in particular, regarding the frequency and distribution of the use of hai and un. Firstly, hai is used mostly by the guests as affirmative responses, backchannels and discourse markers. Un is used more frequently by the hosts while guests refrain from using it. On the other hand, the token ee is used by both the hosts and the guests with roughly similar frequency.

The distribution of these tokens seems directly related to the role of the participants, an observation that has also been noted in other languages such as English and Indonesian (Fuller 2003; Wouk 2001). In their role as interviewers, there are fewer occasions when hosts have to answer a question therefore it is not strange that hai as an answer is used so seldom in their discourse. Most of the guests, on the other hand, use hai and ee as answers. Then again, hosts overwhelmingly use the token un to encourage and promote further talk while the use of un as a backchannel is almost negligible in the speech of the guests. Although this is an expected outcome, since the turn-taking in interviews is more strictly based on question and answer dyads than in ordinary conversation (Clayman and Heritage 2002; Jucker 1986), it is noteworthy that only one guest used the un token as a response. This particular guest is male and much older than the female interviewer, they are acquaintances and the male guest is her senior. Although there are some studies of the difference in usage of backchannels according to gender (Horiguchi 1997), there were no outstanding differences observed in this data.

As discussed in the section on data description, the initial analysis included informal dyadic interactions in which hai was not used at all except in duplicate or triplicated forms. This fact indicates that there is indeed a dimension of formality in the use of hai. However, as this study shows, it is not possible to argue that formality alone can explain the use of the other two tokens.

The difference in distribution of these tokens in the speech of the hosts and guests suggests that hai is more content oriented than un and ee, thus explaining why it is used more frequently by guests, as suggested by Togashi (2002). Guests in the interview situation have to 'understand' the question in order to be able to answer. By providing hai type answers and backchannels, the guest is able to indicate the host his 'understanding' of the content. This also applies when backchannels are sent at points where the guest cannot anticipate the content of the question because the information is not complete, as in examples (13) and (14). By sending the hai token, guests are able to signal alertness and comprehension of the content and meaning of the hosts' utterances. The hosts, on the other hand, do not need to show that they understand what the guest is saying, but in their role of interviewer they should encourage the guest to speak. By using the token un more often than any other token, the host is able to make the guest feel comfortable and encourage him/her to talk (Horiguchi 1997; Tanaka, L. 2004). 
Hosts have the advantage of knowing more about their guests and have prepared questions beforehand. In that sense, too, their role is that of promoting talk rather than showing understanding.

Caffi and Janney (1994) write about the loci of interest and emotive choices. They define three emotive choices depending on which elements are in the foreground. They classify those choices as 'speaker-centered, hearer-centered and content-centered' (Caffi and Janney 1994: 361). It seems that the use of hai, ee and un can be explained along these lines. Hai is content-centered and allows the speaker to show his/her interest and understanding of the content expressed. This observation is reinforced by Togashi's (2002) study of hai and by the examples presented in this study. On the other hand, un is a hearer-centered choice and therefore it is used more frequently by the hosts as a backchannel. Because un is more hearer-centered and it functions more as a conversation management tool, the psychological and social distance between speakers will narrow; thus they might have been associated with informality.

The fact that all hosts use un more often than other tokens indicates that the function of $u n$ is to promote talk, and that it is not particularly related to the meaning/content of what the speaker is saying; therefore it is used for discourse management purposes. Conversely, the fact that hai is not used in informal conversations indicates that in intimate/informal interactions people talk mainly to socialize and that the exchange of information may be secondary whereas the contrary is the case in an interview. This might account for why un is used more often by the hosts than the guests; the host needs to provide the appropriate environment to encourage the guest to talk. The guest, on the other hand, has to primarily understand the meaning of the questions and be able to process that information before answering, both while listening to the question and when answering. Interviews are goal oriented activities, quite different to mundane everyday conversations, and in particular when they are 'institutional' interactions (Clayman and Heritage 2002; Drew and Heritage 1992). The goal of the interview is to obtain information from the interviewee and participants are aware of the 'institutional' nature of the interaction. Whereas interactions between friends in casual conversation have no particular agenda other than to socialize, interactions during interviews are governed by strict role allocation and rules.

$E e$, on the other hand, seems to be more neutral and not restricted to meaning or social-relationship-building. It is used in informal data in initial position but in these cases it seems to function not as a response to a question but as a signal of interest or floor-taking (Angles et al. 2002). In the present data, there were a small number of examples that allowed us to see that when the function of ee is not that of answering a question or request, it is that of showing attention.

Togashi's (2002) observations, based on Chafe's activation cost theory (1994), which explain that hai is effective in retrieving new information while un is less successful are relevant to this study. However, the distribution of hai and un in the discourse of the hosts and guests would seem to suggest that it is not the use of hai itself that retrieves more information. Rather, the emotive choice of hai puts the content of the talk in the foreground whereas un places the hearer in the foreground (Caffi and Janney 1994).

It seems, therefore, that the difference between hai, ee and un lies in their emotive value. Hai is content-centered and its focus is on the logical/information content aspect; un is hearer-centered and the listener is in the foreground. The token ee is more difficult to explain. The fact that both, hosts and guests, use them in almost equal numbers indicates that the difference between hai and ee in terms of speaker role is minimal. However, the most important feature is that ee seems to be used for other functions that are not similar to un and hai (as surprise markers, dissalignment to a previous assessment, resistance to a question (Hayashi 2009)) and it might be a more speaker-centered token. This point might be associated with the fact that its original meaning was used to indicate surprise (Mori, Y. 1993). 
Many studies on discourse markers and other lexical elements have described their process of grammaticalization and intersubjectification (Onodera 2004; Traugott 2007, Wang, Katz and Chen 2003; Wang, Tsai and Ling 2007). It is evident that through this process many lexical items have changed from the propositional to the expressive levels. The fact that hai, ee and un are polyfunctional suggests that they are going through a process of intersubjectification (Traugott and Dasher 2002). From their original role as answers to a yes/no question they have now come to be used as interactional tools. While originally hai was used as an answer in formal situations towards one's superiors, the token ee was used as an interjection denoting surprise as explained previously (Mori, Y. 1993). On the other hand, un used to indicate acknowledgment is a more recent word in the history of the Japanese language. The fact that these three tokens are nowadays used as not only answers to $\mathrm{Y} / \mathrm{N}$ questions but also as backchannels and discourse markers that show the speaker's stance, indicates that the changes they are undergoing are towards an interactional level.

\section{Conclusion}

The present study has looked at three response tokens hai, ee and un in formal interactions. Despite the fact that un and ee are considered to be informal, the speakers in the data use them very frequently but according to a distribution pattern directly correlated to the speaker's role. These tokens are polyfunctional and are used not only as answers but also as backchannels and discourse markers. The tokens hai and ee are overwhelmingly used by guests as answers to questions while hosts use un overwhelmingly as backchannels.

From the viewpoint of emotive communication, hai seems to be content-centered, and this might be the reason why it conveys a feeling of deference and is associated with formal interactions. On the other hand, un seems to be hearer-centered, and is therefore used as a backchannel by the hosts. Ee is more difficult to classify, and this may perhaps be attributed to its original meaning of surprise rather than that of agreement.

The present results suggest that these tokens are going through a process of intersubjectification in which their original propositional meaning is changing towards a more expressive level. While further studies of the diachronic changes of these three tokens would confirm observations on intersubjectification, it is hoped that this study has provided new viewpoints in the research of hai, ee and un.

\section{Transcription Conventions}

The following conventions suggested by Du Bois, Schuetze-Coburn, Paolino and Cumming (1990) were used for the transcription of the data.

$\begin{array}{lll}\text { Hyphen } & (-) & \begin{array}{l}\text { Truncated word } \\ \text { Continuing intonation unit, usually signaled by } \\ \text { Comma }\end{array} \\ & (,) & \begin{array}{l}\text { intonational, semantic and/or syntactic factors } \\ \text { Completed intonation unit }\end{array} \\ \text { Full-stop } & (.) & \text { Question } \\ \text { Question mark } & (?) & \text { Laughter }\end{array}$




$\begin{array}{lll}\text { Square brackets } & ([]) & \text { Simultaneous speech } \\ \text { Two dots } & (. .) & \text { Brief pause, 0.2 seconds or less } \\ \text { Three dots } & (\ldots) & \text { Medium pause, 0.3- 0.6 seconds } \\ \text { Three dots plus } & (\ldots .(0.7)) & \text { Long pause with number indicating duration in } \\ \text { number } & & \text { seconds } \\ \text { Single brackets } & (\text { sneeze) } & \text { Indicates type of vocal noise } \\ \text { Double brackets } & ((\text { gaze })) & \text { Indicates comment by researcher } \\ \text { Capital X } & (X) & \text { Indicates indecipherable syllable } \\ \text { Single brackets } & (\text { yes }) & \text { backchannel } \\ \text { bold } & & \\ \text { Equal sign } & (=) & \text { Vowel lengthening } \\ \text { Diagonal line } & (/) & \text { Rising intonation } \\ \text { Capital letters } & \text { TEXT } & \text { marked quality }\end{array}$

\section{References}

Akio, Kamio (1997) Territory of Information. Amsterdam: John Benjamins Publishing Company.

Angles, Jeffrey, Ayumi Nagatomi, and Nakayama Mineharu (2000) Japanese responses hai, ee, and un: Yes, no, and beyond. Language and Communication 20: 55-86.

Brinton, Laurel (1996) Pragmatic Markers in English. Grammaticalization and Discourse Functions. Berlin: Mouton de Gruyter.

Caffi, Claudia, and Richard W. Janney (1994) Towards a pragmatics of emotive communication. Journal of Pragmatics 22: 251-64.

Chafe, Wallace (1994) Discourse, Consciousness and Time: The Flow and Displacement of Conscious Experience in Speaking and Writing. Chicago: The University of Chicago Press.

Clayman, Steven, and John Heritage (2002) The News Interview: Journalists and Public Figures on The Air. Cambridge: Cambridge University Press.

Danes, Frantisek (1994) Involvement with language and in language. Journal of Pragmatics 22: 251-264.

Drew, Paul, and John Heritage (1992) Analyzing Talk at Work. Cambridge: Cambridge University Press.

Du Bois, John., Stephan Schuetze-Coburn, Danae Paolino, and Susanna Cumming (1990) Outline of discourse transcription. In Jane A. Edwards and Martin D Lampert (eds.), Transcription and Coding Methods for Language Research. Hillsdale, NJ: Lawrence Erlbaum.

Fuller, M. Janet (2003) The influence of speaker roles on discourse marker use. Journal of Pragmatics 35: $23-45$.

Fischer, Kerstin (2006) Towards and understanding of the spectrum of the approaches to discourse 
particles: Introduction to the volume. In K. Fischer (ed.), Approaches to Discourse Particles. Amsterdam: Elsevier, pp. 1-20.

Furo, Hiroko (2001) Turn-Taking in English and Japanese. Projectability in Grammar, Intonation and Semantics. London: Routledge.

Gardner, Rod (2001) When Listeners Talk. Amsterdam: John Benjamins Publishing Company.

Goody, Esther (1978) Questions and Politeness. Cambridge: Cambridge University Press.

Gupta, Anthea Fraser (2006) Epistemic modalities and the discourse particles of Singapore. In K. Fischer (ed.), Approaches to Discourse Particles. Amsterdam: Elsevier, pp. 243-264.

Guruupu Jamashii (1998) Nihongo bunkei jiten. Tokyo: Kuroshio.

Hayashi, Makoto (2009) Marking a 'noticing of departure' in talk: Eh-prefaced turns in Japanese conversation. Journal of Pragmatics 41: 2100-2129.

Horiguchi, Junko (1997) Japanese Conversation by Learners and Native Speakers. Tokyo: Kuroshio.

Iwasaki, Shotaro (1997) The Northridge earthquake conversations: The floor structure and the 'loop' sequence in Japanese conversation. Journal of Pragmatics 28: 661-693.

Jucker, Andreas (1986) News Interviews: A Pragmalinguistic Analysis. Amsterdam: John Benjamins Publishing Company.

Jucker, Andreas, and Yael Ziv (1998) Discourse Markers: Descriptions and Theories. Amsterdam: John Benjamins Publishing Company.

Jucker, Andreas, and Sara Smith (1998) And people just know like 'wow'; Discourse markers and negotiating strategies. In A. Jucker, H.Y. Ziv, (eds.), Discourse Markers: Descriptions and Theories. Amsterdam: John Benjamins Publishing Company, pp. 171-1201.

Kitagawa, Chisato (1980) Saying 'yes' in Japanese. Journal of Pragmatics 4: 105-120.

Kuno, Susumu (1973) The Structure of the Japanese Language. MIT Press: Cambridge.

Komiya, Chizuru (1986) Aizuchi shiyoo no jittai - shutsugen keikoo to sono shuuhen. Gogaku Kyooiku Kenkyuu Ronsoo. Daitoo Bunka Daigaku Gogaku Kyooiku Kenkyuujoo.

Kurosaki, Yoshiaki (1987) Danwa shinkoojoo no aizuchi no unyoo to kinoo [The functions and management of aizuchi in the conversation]. Kokugogaku 150.15: 122-109.

Lerner, Gene, and Tomoyo Takagi (1999) On the place of linguistic resources in the organization of talk-in-interaction: A co-investigation of English and Japanese grammatical practices. Journal of Pragmatics 31.1: 49-75.

Martin, Samuel (1962) Essential Japanese: An Introduction to the Standard Colloquial Language. Rutland. VT: Charles E. Tuttle Company.

Matsumoto, Yoshiko (1988) Reexamination of the universality of face: Politeness phenomena in Japanese. Journal of Pragmatics 12: 403-426.

Maynard, Senko (2002) Linguistic Emotivity. Centrality of Place, the Topic-Comment Dynamic, and an Ideology of Pathos in Japanese Discourse. Amsterdam: John Benjamins Publishing Company. 
Maynard, Senko (1986) On back-channel behaviour in Japanese and English casual conversation. Linguistics 24: 1079-1108.

McGloin, Naomi Hanaoka (1990) Sex difference and sentence-final particles. In S. Ide and N. Hanaoka McGloin (eds.), Aspects of Japanese Women's Language. Tokyo: Kurosio, pp. 23-41.

Mori, Junko (1999) Negotiating Agreement and Disagreement in Japanese. Connective Expressions and Turn Construction. Amsterdam: John Benjamins Publishing Company.

Mori, Yoshiyuki (1993) Kiso Nihongo Jiten. Tokyo: Kadokawa Shoten.

Okamoto, Shigeko (1985) Ellipsis in Japanese Discourse. Unpublished Ph.D. Dissertation. University of California.

Okutsu, Keichiro (1989) 'Hai' to 'iie' no kinou. In K. Inoue (ed.), Nihongo-no Fuhensei-to Kobetsusei-ni kan-suru Rironteki Oyobi Jisshooteki Kenkyuu Kenkyuu Hookoku 4: 133-182.

Onodera, Noriko (2004) Japanese Discourse Markers. Amsterdam: John Benjamins Publishing Company.

Pomerantz, Anita (1984) Agreeing and disagreeing with assessments: Some feature of preferred/dispreferred turn shapes. In John Maxwell Atkinson and John Heritage (eds), Structures of Social Interaction: Studies in Conversation Analysis. Cambridge: Cambridge University Press, pp. 57-101.

Sacks, Harvey, Emmanuel Schegloff, and Gail Jefferson (1974) A simplest systematics for the organization of turn-taking for conversation. Language 50-4: 696-735.

Suzuki, Satoko (2006) Emotive Communication in Japanese. Amsterdam: John Benjamins Publishing Company.

Tanaka, Hiroko (1999) Turn Taking in Japanese Conversation. A Study in Grammar and Interaction. Amsterdam: John Benjamins Publishing Company.

Tanaka, Lidia (2004) Language, Gender and Culture. Amsterdam: John Benjamins Publishing Company.

Togashi, Junichi (2002) 'Un' to ‘hai’ no kankei o megutte. In T. Sadanobu (ed.), ‘Un’to ‘so’no gengogaku. Tokyo: Hitujisyobo, pp. 127-157.

Traugot, Elizabeth C. (1995) The role of the development of discourse markers in a theory of grammaticalization. Paper presented at ICHL XII, Manchester 1995. Version of 11/97. http://www.stanford.edu/ traugott/papers/discourse.pdf

Traugott, Elizabeth (2007) Discussion article: Discourse markers, modal particles, and contrastive analysis, synchronic and diachronic. Catalan Journal of Linguistics 6: 139-157.

Traugott, Elizabeth, and Richard Dasher (2002) Regularity in Semantic Change. Cambridge: Cambridge University Press.

Wang, Yu-Fang, Aya Katz, and Chih-Hua Chen (2003) Thinking as saying: shuo ('say') in Taiwan Mandarin conversation and BBS talk. Language Sciences 25: 457-488.

Wang, Yu-Fang, Pi-Hua Tsai, and Meng-Ying Ling (2007) From informational to emotive use: Meiyou ('no') as a discourse marker in Taiwan Mandarin conversation. Discourse Studies 9: 677-701.

Wouk, Fay (2001) Solidarity in Indonesian Conversation: The discourse marker ya. Journal of Pragmatics 
33: 171-191.

Yngve, Victor H. (1970) On getting a word in edgewise. In Papers from the 6th regional meeting. Chicago: Chicago Linguistic Society, pp. 567-578.

LIDIA TANAKA is lecturer in the Asian Studies Division of the School of Sociology, Anthropology and Politics at La Trobe University. She obtained her Ph.D. in linguistics in 2001 and her research interests are in language and gender in Japan, Conversation Analysis and the language in interviews. She is the author of Gender, language and culture: A study of Japanese television interview discourse (John Benjamins Publishing Company, 2004).

Address: Asian Studies, School of Humanities and Social Sciences, La Trobe University, 3086, Bundoora, Victoria, Australia; e-mail: 1.tanaka@latrobe.edu.au 